\title{
BEZBEDNOSNI ZAHTEVI OLIMPIJSKIH IGARA
}

\author{
Violeta Šiljak ${ }^{1}$, Vladan Vukašinović ${ }^{2}$ i Dejan Đurović ${ }^{1}$ \\ ${ }^{1}$ Fakultet za menadžment u sportu, Alfa BK Univerzitet, Srbija \\ ${ }^{2}$ Fakultet sporta i fizičkog vaspitanja Univerziteta u Beogradu, Srbija
}

\section{Originalni naučni članak}

\section{SAŽETAK}

Predmet ovog rada se odnosi na bezbednosne zahteve na olimpijskim igrama. Olimpijske igre su najveća globalna sportska manifestacija, koja okuplja sportiste i gledaoce iz preko 200 država širom sveta. Fenomenološki aspekti sporta - društveni, politički i ekonomski faktori su neki od razloga njihove planetarne popularnosti. Nažalost, veliki događaji su oduvek privlačili pažnju terorista, raznih organizacija i pojedinaca koji su na njima videli priliku da na nehuman način skrenu pažnju na sebe zarad ciljeva koji nisu povezani sa sportom, već sa politikom $i$ ostalim problemima. Iz tih razloga, bezbednosni zahtevi olimpijskih igara veoma su bitni $i$ oni su, između ostalog, jedan od primarnih zadataka organizacije svakih olimpijskih igara. Cilj ovog rada je da se ukaže na potrebu i značaj primene bezbednosnih mera tokom održavanja olimpijskih igara. Pored opšte bezbednosti svih učesnika i gledalaca od neželjenih faktora, treba imati u vidu $i$ bezbednost sportista od povreda. U svrhu obezbeđenja sportista, trenera, menadžera, delegacija, sudija, publike i specijalnih VIP gostiju domaćini igara uz međunarodnu pomoć preduzimaju posebne mere. Analizirajući posvećenost organizacionih komiteta gradova domaćina u XXI veku u polju bezbednosti, rezultati rada ukazuju na neophodnost primene bezbednosnih mera tokom održavanja olimpijskih igara u cilju sprečavanja njihove zloupotrebe od strane negativnih elemenata.

Ključne reči: mere bezbednosti, terorizam, olimpijske igre.

\section{UVOD}

Olimpijske igre su od svog nastanka predstavljale sportski događaj koji je, osim sportske, imao još jednu veoma bitnu dimenziju - bezbednost. Iako su savremene olimpijske igre nastale na principima antičkih olimpijskih igara, danas, posle 120 godina od njihove obnove, mogu da se uoče njihove sličnosti i razlike posmatrajući ih sa bezbedonosnog aspekta.

Zbog velikog broja ratova među grčkim polisima, koji su za posledicu imali veliki broj ranjenih i mrtvih, što je dovodilo i do siromašenja polisa, prema savetu Delfskog proročišta uspostavljena je ekeherija, odnosno Sveti mir. Sporazum koji su na metalnom disku potpisala tri grčka kralja postao je osnova Svetog mira među grčkim polisima u vreme održavanja igara. Pored prestanka 
ratova, ovaj sporazum je podrazumevao i nepovredivost same Olimpije, kao i imunitet svih posetilaca. Zahvaljujući Svetom miru svi takmičari, zvanični predstavnici grčkih državica i ostali građani su dolazili, boravili i potpuno bezbedno se vraćali u svoje gradove, bez straha da im se nešto u putu dogodi. U početku igara Sveti mir je trajao jedan mesec da bi se kasnije produžio na tri meseca i poštovan je od strane svih Grka kao neprikosnoveni zakon. Osim produženja vremenskog trajanja mira, njegovo dejstvo se proširilo i na čitav region oko Olimpije, tako da je cela Elida bila proglašena Svetom zemljom. To je podrazumevalo zabranu pristupa svim naoružanim ljudima, kao i svih ratova.

Primirje je poštovano kroz 12 neprekidnih vekova održavanja olimpijskih igara sa retkim izuzecima. Kazne za prekršioce primirja su bile veoma stroge. Iako Sveti mir nije dozvoljavao unošenje oružja u Svetilište tokom trajanja igara, 364. godine pre n. e. zabeležen je slučaj kada je došlo do borbe u Olimpiji za vreme Igara (Ksenofont, 1988). U pokušaju Elejaca da povrate upravu nad Svetilištem vodili su borbu čak i na Altisu protiv Pizana. Kasnije, te olimpijske igre oni nisu računali da su se održale.

Ovim korisnim proročanstvom iskorišćena je mirovna dimenzija sporta, njegova mogućnost da preobrazi ljudsku agresivnost u mirovno takmičenje i istovremeno da pruži šansu neprijateljima da se sretnu, da se zajedno bore i upoznaju u miru na istom stadionu. Postojala je i jedna ,realpolitička“ dimenzija: najbolji sportisti su bili obično ratnici, pa prema tome nije bilo moguće da učestvuju u igrama ako privremeno ne prestanu da se bore. Dodatno, kako sportisti tako i obični gledaoci bili su primorani da putuju u Olimpiju uglavnom kopnom (Šiljak, 2013).

Međutim, ljudski faktor kao uzročnik svih zbivanja isti je kao i pre tri milenijuma. Danas su na olimpijskim igrama prisutne sporne sudijske odluke, korišćenje doping sredstava da bi se pobedilo po svaku cenu, amaterizam, koji je prerastao u profesionalizam ${ }^{1}$, politički bojkoti, terorizam, komercijalizacija. Ove negativne situacije sa kojima se MOK susretao proizvele su i njegovu pozitivnu reakciju u cilju očuvanja olimpijskog duha igara, te se sprovode veoma stroge mere bezbednosti prilikom organizacije igara. Tako, veliki broj volontera se uključuje kao ispomoć, osnovan je Olimpijski pokret za mir po ugledu na antičku ekeheriju, osnovan je fond solidarnosti za pomoć sportistima, ostvarena je saradnja sa Antidoping agencijom i dr. (Šiljak, 2013).

Problem ovog rada odnosi se na bezbednost igara tokom njihovog trajanja, s kojom se suočavaju organizatori. Bezbednost je veoma širok pojam imajući u vidu da se može poći od bezbednosti pojedinca do bezbednosti čitave nacije ili globalnog sportskog događaja. Razvoj savremene tehnologije obezbeđuje takvu opremu za OI, koja se zasniva na najnovijoj tehnologiji, kako bi se ceo događaj osigurao od neželjenih incidenata.

\footnotetext{
${ }^{1}$ Jedan od pet principa po kojima su zasnovane Olimpijske igre 1894. godine bio je da na Igrama mogu učestvovati samo amateri. Tumačenje ovog principa je u olimpijskoj istoriji dovodilo do nemilih i nepopularnih odluka sudija. Osavremenjavanje igara je uticalo na njegovu promenu i od 1988. godine na Igrama pravo učešća imaju i profesionalni sportisti.
} 
Predmet ovog rada se odnosi na bezbednosne zahteve na olimpijskim igrama, najvećoj sportskoj globalnoj manifestaciji. Tokom 120 godina održavanja modernih olimpijskih igara prateći događaji diktirali su povećanje mera bezbednosti na njima, a posledično i povećanje bezbednosnih zahteva. Cilj ovog rada je da se ukaže na značaj i potrebu primene bezbednosnih mera tokom održavanja olimpijskih igara i spreči njihova zloupotreba od strane negativnih elemenata.

\section{Savremene olimpijske igre $i$ bezbednost}

Globalizacija danas ima pored svojih pozitivnih i svoju negativnu stranu. Sport se, na žalost, ne može odvojiti od uticaja ekonomskih i političkih faktora, bilo direktno ili indirektno. Komercijalizacija, profesionalizam, nadmetanje za domaćina olimpijskih igara su njihovi pokazatelji.

Bezbednost na olimpijskim igrama u početku njihovog održavanja odnosila se uglavnom na same aktere igara, da bi danas postala mnogo kompleksnija oblast, kojom se bave čitavi naučni timovi.

Prvi svetski rat onemogućio je održavanje VI olimpijskih igara za koje je bilo planirano da budu održane u Berlinu 1916. godine. Organizacija XII igara, zakazanih za 1940. godinu, poverena je Tokiju, a nakon izbijanja Drugog japansko-kineskog rata dodeljena je Helsinkiju. To takmičenje je, međutim, otkazano zbog Drugog svetskog rata, kao i sledeće igre, čiji je domaćin trebalo da bude London 1944. godine. Zbog bezbednosti učesnika i posetilaca igre su u XX veku tri puta otkazane, dok su kod starih Grka ratovi prestajali zbog igara. U naše vreme MOK ulaže veliki napor za oživljavanje institucije olimpijskog primirja sa teško dostižnim ciljem prestanka neprijateljstava za vreme svih budućih olimpijskih igara, ali i nakon njihovog završetka sa krajnjim ishodom - mirnim rešenjem svih razlika.

Na primerima nemilih događaja sa Olimpijskih igara iz Minhena 1972, Atlante 1996. i Atine 2004. godine mogu se uočiti tri različita načina ugrožavanja bezbednosti olimpijskih igara. Minhenske igre, održane od 26. avgusta do 11. septembra 1972. godine, bile su do tada najveće održane, ali zauvek će ostati upamćene po tragičnom događaju od 5. septembra, kada su u olimpijsko selo upali teroristi, pripadnici palestinske organizacije „Crni septembar“ i ubili dvojicu izraelskih predstavnika, a devetoricu uzeli za taoce (Sl. 1). Posle neuspešne akcije spašavanja na minhenskom aredoromu svi taoci su ubijeni, kao i petorica terorista i jedan nemački policajac. Usledio je 34-časovni prekid Igara, ali su nakon održavanja pomena preminulim sportistima Igre ipak nastavljene odlukom MOK-a uz podršku izraelskih zvaničnika, ali bez sportista te zemlje. 


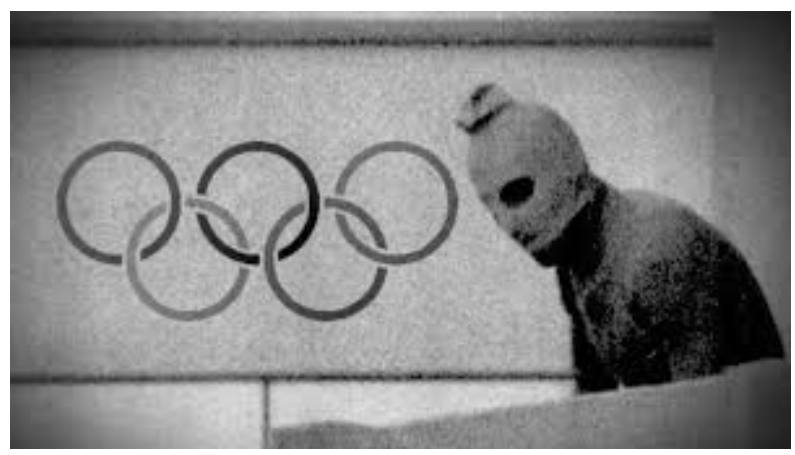

Sl.1 - Palestinski terorista u Minhenu 1972. godine

Čin organizovanog terorističkog napada na izraelske sportiste 1972. godine u Minhenu je iznenadio ceo svet, a igre od tog dana više nikada nisu bile iste. Mnoge zemlje su tokom kriza poput hladnog rata bojkotovale olimpijske igre, a policija, pa čak i vojska, osiguravali su sportiste kao da su najviši politički predstavnici. Upravo to je u određenoj meri uspelo da spreči svaki dalji pokušaj terorističkih napada na prestižnim sportskim događajima.

Kada je 20 kilograma teška bomba eksplodirala u Olimpijskom parku 1996. godine u Atlanti, poginule su dve osobe, a 111 ih je bilo ranjeno (Sl. 2). Ove dve lekcije su veoma poučne, posebno za zemlje organizatore olimpijskih igara. Potcenjivanje ovakvih događaja u narednom periodu moglo bi dodatno da pogorša i iskomplikuje bezbednost na olimpijskim igrama.

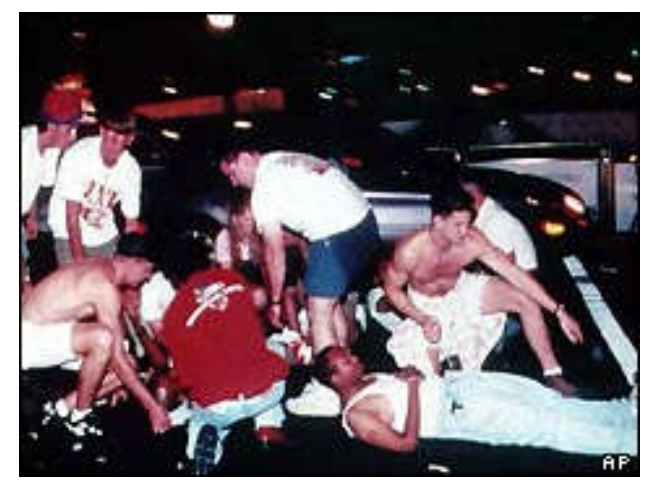

S1. 2 - Žrtve bombaškog napada u Atlanti 1996. godine

U Atini 2004. godine se dogodio specifičan napad na takmičara tokom trke. U maratonskoj trci, sedam kilometara pre cilja, do tada vodećeg Brazilca Vanderleja de Limu, u trenutku kada je imao prednost od 48 sekundi u odnosu na najbližeg konkurenta, napao je jedan gledalac, za koga se kasnije utvrdilo da je irski sveštenik, i potpuno ga izbacio iz ritma (Sl. 3). To su iskoristili njegovi protivnici, pa je Italijan Stefano Baldini osvojio zlatnu medalju, dok je Lima na cilj stigao tek treći. MOK je naknadno uručio priznanje „Pjer de Kuberten“ brazilskom sportisti. 


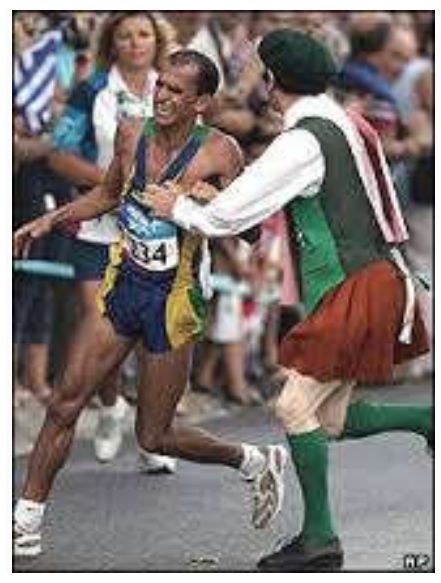

Sl. 3 - Napad na Vanderleja de Limu tokom maratonske trke.

Iako je teroristički napad tokom Igara u Minhenu 1972. godine bio prekretnica na polju bezbednosti ove sportske manifestacije, tek od Olimpijskih igara u Atini 2004. godine se može uočiti globalna povezanost svih bezbednosnih agencija u cilju bezbednog proticanja celog događaja. Međutim, i pored relativno dobrih bezbednosnih mera u Atini, prethodni primer ukazuje na činjenicu da su propusti uvek mogući. Olimpijske igre su pomerile granice sporta sa više aspekata i tako uzrokovale sukob različitih interesa, što je i najvažniji argument za naglašavanje pitanja sigurnosti igara. Bezbednost i sport su dva bitna elementa života svakog čoveka. Čovek je oduvek težio zdravom telu i duhu, ali i bezbednosti kao preduslovu da to ostvari.

Terorizam danas, kao pretnja celom svetu pa i olimpijskim igrama, svakako se smatra prioritetnom opasnošću pred kojom se sve svetske bezbednosne agencije udružuju u cilju njegovog sprečavanja. Odgovornost organizatora, odnosno organizacionog odbora grada domaćina je velika i prenosi se na celu državu i kao takva smatra se jednim od njihovih najtežih zadataka. Međutim, postoje i druge opasnosti koje treba preduprediti i koje pripadaju oblasti bezbednosnog menadžmenta, a to je bezbednost takmičara tokom nadmetanja. To podrazumeva bezbedne sportske objekte, opremu i dr. u odnosu na mogućnost povređivanja samih takmičara. Ukoliko se zimske olimpijske igre mogu smatrati bezbednijim po pitanju terorističkih napada, toliko su one zbog svojih specifičnih sportskih staza i disciplina mogu smatrati opasnijima po život samih takmičara. Takmičenja u zimskom sportu se graniče sa ekstremnim po pitanju težine staza. Nesreća sa smrtnim ishodom koja se dogodila u Vankuveru na ZOI 2010. godine potvrđuje tu činjenicu. Nodar Kumaritašvili, sankaš iz Gruzije, poginuo je na stazi tokom treninga (Sl. 4). Igre su morale da se nastave, ali se postavlja pitanje da li su organizatori u želji da naprave što atraktivniju stazu zaboravili na bezbednost iste. 


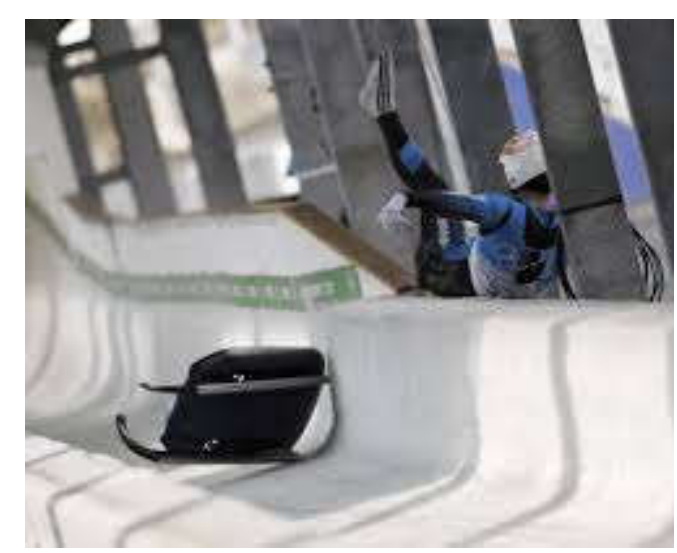

Sl. 4 - Nodar Kumaritašvili neposredno nakon kobnog pada

Ruska skijašica Marija Komisarova je na poslednjim održanim Zimskim olimpijskim igrama održanim u Sočiju 2014. godine zadobila povredu kičme nakon koje neće moći više da hoda. Na Igrama u Sočiju je bio veliki broj povreda, međutim, zvanični izveštaj MOK je da je bio isti kao i na prethodnim Igrama u Kalgariju (http://www.olympic.org/news/ioc-injury-illness-surveillancestudy-protecting-the-athletes-health/225531). Navodi se da je posebna Medicinska komisija MOK tokom Igara pratila sve takmičare i beležila svaku povredu. Njihovim daljim istraživanjama, kao i istraživanjima naučnika u oblasti medicine trebalo bi da se nađu rešenja za što bezbednije uslove za takmičare. Postavlja se pitanje da li lekari mogu da utiču na manje atraktivnu, ali bezbednu stazu, koja kao takva ne odgovara organizatorima jer ne privlači dovoljno pažnje.

Na olimpijskim igrama je do sada izgubilo život tokom takmičenja osam sportista (4 na ZOI i 4 na LOI). Van takmičenja je u različitim nesrećama izgubilo život četrnaest sportista, a od tog broja je jedanaest njih poginulo u Minhenu 1972. godine. Postoje podaci i o nastradalim posetiocima olimpijskih igara koji nisu precizni. U Meksiku 1968. godine stradao je veliki broj meksičkih studenata koji su protestvovali tokom Igara; u Atlanti 1996. godine prilikom bombaškog napada poginulo je dvoje, a ranjeno 111 ljudi, dok su u Londonu 2012. godine zabeležena dva smrtna ishoda, gde je na jednog biciklistu naleteo autobus koji prevozi timove do borilišta (http://en.wikipedia.org/wiki/Olympic_deaths).

\section{Organizacija igara}

Menadžment jednog sportskog događaja je kompleksan, jer je neophodno da prati od početka do kraja sam događaj. Menadžment olimpijskih igara mora da sadrži sve elemente menadžmenta od planiranja i organizovanja do vođenja i kontrole, radi uspešne realizacije. Pitanja zdravstvene zaštite i bezbednosti uz istovremeno vođenje računa o potencijalnim finansijskim rizicima razmatraju se u okviru projekta menadžmenta rizicima. Pripremajući ovaj sportski događaj, organizator teži da eliminiše ili svede na najmanju moguću meru događaje ili aktivnosti koji mogu poremetiti učesnike događaja (takmičare, gledaoce ili službenike). 
Operativne aktivnosti vezane za organizaciju takmičenja podrazumevaju snabdevanje objekta neophodnom opremom, kao i obezbeđivanje svih drugih uslova i operativnih aktivnosti neophodnih za uspešno odvijanje sportskog događaja: mesto održavanja, sportska oprema, tačan raspored planiranih aktivnosti, sponzorstvo, bezbednost, kontrolisanje mase, mediji i promotivne aktivnosti i drugo.

Sa organizacionog aspekta, olimpijske igre predstavljaju ogroman poduhvat i izazov za Međunarodni olimpijski komitet, organizacione komitete, kao i grad i zemlju domaćina. Organizacija olimpijskih igara predstavlja složen i dinamičan proces koji se neprekidno menja. Aktuelni problemi organizacije, tj. menadžmenta igara u celini, zaokupljaju pažnju stručne i sportske javnosti, a nalaze se i u sferi interesovanja „običnih“ gledalaca. Organizacija olimpijskih igara poverena je od strane MOK-a nacionalnom olimpijskom komitetu zemlje grada domaćina, kao i samom gradu domaćinu. U tu svrhu NOK ima dužnost da osnuje organizacioni komitet olimpijskih igara koji od momenta kada je konstituisan direktno izveštava Izvršni odbor MOK-a. Organizacioni komitet olimpijskih igara ima status pravnog lica u zemlji grada domaćina. Izvršni organ organizacionog komiteta olimpijskih igara obuhvata: člana MOK-a, predsednika i generalnog sekretara NOK-a i najmanje jednog člana koga je odredio grad domaćin. On takođe može uključivati i predstavnike javne vlasti ili druge vodeće ličnosti. Organizacioni komitet olimpijskih igara mora delovati u skladu sa Olimpijskom poveljom.

Menadžment olimpijskih igara podrazumeva da budući organizacioni komitet olimpijskih igara počinje kandidaturom svog grada za domaćina OI, a završava se predajom izveštaja MOK-u po završetku igara (Škaro, 2012). Isti autor strukturira olimpijske igre u faze:

- Ideja i izvodljivost

- Takmičenje za prihvatanje projekta

- Izgradnja i priprema za igre

- Održavanje olimpijskih igara i

- Zatvaranje igara i korišćenje olimpijskog nasleđa.

U cilju okupljanja svih takmičara, zvaničnika i drugog osoblja timova na jednom mestu, organizacioni komitet olimpijskih igara mora da obezbedi olimpijsko selo za period koji utvrđuje Izvršni odbor MOK-a. Olimpijsko selo mora ispunjavati sve zahteve utvrđene od strane Izvršnog odbora MOK-a, kao što su na primer kvote za smeštaj delegacija zemalja.

Organizacioni komitet olimpijskih igara mora da obezbedi odgovarajući smeštaj i službene prostorije ukoliko se određene manifestacije dešavaju na lokaciji koja nije u gradu domaćinu igara, a u skladu sa zahtevima Izvršnog odbora MOK-a. Takođe, dužan je da organizuje različite događaje kulturnog programa u periodu celokupnog trajanja olimpijskog sela. Kulturni program, pre njegove realizacije, mora biti dostavljen na odobrenje Izvršnom odboru MOK-a. 
Da bi najpre takmičari, a onda treneri i drugi članovi delegacije mogli uzeti učešće na olimpijskim igrama, oni moraju da poštuju Olimpijsku povelju, uključujući uslove o podobnosti utvrđene od strane MOK-a, kao i pravila određene Međunarodne federacije.

Tokom organizacije olimpijskih igara praksa je pokazala da je planirani budžet za njihovu organizaciju uvek premašivan. Imajući u vidu činjenicu da se broj potencijalnih opasnosti po bezbednost igara uvećao i troškovi njihove organizacije su sve veći. Teško je utvrditi, odnosno doći do zvaničnih podataka koliko je od tog budžeta potrošeno na bezbednosni segment igara, naročito ako se ima u vidu činjenica da se bezbednost ne odnosi samo na učesnike, već i na druga lica i objekte. Na Sl. 5 dat je tabelarni prikaz utrošenih sredstava za organizaciju igara na izabranim primerima.

\begin{tabular}{|c|c|c|}
\hline GODINA & GRAD DOMAĆ IN & BUDŽET \\
\hline 1992. & Barselona & 9,3 milijardi \$ \\
\hline 2002. & Solt Lejk Siti & 1,2 milijarde \$ \\
\hline 2004. & Atina & 9 milijardi \$ \\
\hline 2010. & Vankuver & 2,3 milijarde \$ \\
\hline 2012. & London & 14,6 milijardi \$ \\
\hline 2014. & Soči & 51 milijarda \$ \\
\hline
\end{tabular}

Sl. 5 - Tabelarni prikaz utrošenih sredstava za organizaciju OI

Ako se uporede Igre iz Solt Lejk Sitija i Vankuvera, uočavamo da su one u Vankuveru za organizaciju potrošile duplo veću sumu. Kako zbog geografskog položaja, prirodnih resursa, broja takmičara i posetilaca ni u čemu do sada nisu poređene zimske i letnje olimpijske igre, ne može se ignorisati činjenica da su do OI u Sočiju 2014. godine ove brojke bile u korist letnjih OI. Rusija je na celokupnu organizaciju Igara potrošila 51 milijardu dolara i time prevazišla sve dosadašnje troškove organizacije igara od njihovog početka pa do danas. Ruska federalna služba bezbednosti je angažovala četiri puta veći broj članova obezbeđenja tokom Igara nego na Igrama u Londonu 2012. godine. Uz to je primenjen višestruki bezbednosni sistem sa opsežnim merama nadzora, koje uključuju dronove, izviđačke robote za otkrivanje eksploziva, superbrze čamce i podmornice koje koriste sonar za otkrivanje potencijalnih pretnji koje dolaze sa mora (Marković, Draganović i Radošević, 2014). Pretpostavka je koliko je novca otišlo na njihovo obezbeđenje, ali primer za to mogu biti troškovi Organizacionog komiteta za Igre u Londonu 2012. godine, koji su na ukupno potrošenu sumu od 14,6 milijardi dolara iznosili oko 1 milijarde dolara.

Za bezbednost na narednim Olimpijskim igrama koje će se održati u Rio de Žaneiru 2016. godine, pored višeslojnog državnog bezbednosnog tela, angažovana je Izraelska bezbednosna kompanija po ceni od 2,2 milijarde dolara. Luiz Fernando Korea je direktor bezbednosti u timu Organizacionog komiteta domaćina, koji je koordinirao na istim poslovima i tokom održavanja Panameričkih igara u Riu 2007. godine.

\section{Zahtevi bezbednosti na olimpijskim igrama}


Organizacioni komiteti olimpijskih igara u saradnji sa MOK planiraju i donose dokumente prema kojima se sprovodi tekuća priprema za Olimpijske igre, kao i samo njihovo sprovođenje.

Ovi zvanični dokumenti se planiraju u skladu sa mestom održavanja olimpijskih igara i kao takvi sadrže posebne odredbe koje se odnose na bezbednost tokom njihovog trajanja. Da bi se uspostavila što bolja spremnost od nepoželjnih događaja, postavljaju se odrednice ili prioriteti koji se smatraju za moguće krizne situacije.

Na osnovu takvog dokumenta, za Olimpijske igre održane 2012. godine u Londonu zahtevi bezbednosti su bili usredsređeni na sledeće pretnje:

- terorizam,

- ozbiljni kriminal,

- domaći ekstremizam i javni neredi i

- prirodne katastrofe.

Dokument koji se odnosi na bezbednost povodom nastupajućih Olimpijskih igara koje će se održati u Rio de Žaneiru 2016. godine povećao je broj bezbednosnih zahteva od pretnji - ili ih je možda detaljnije predstavio, a to su:

- građanska neposlušnost,

- kriminal,

- tehnološki rizici,

- saobraćaj,

- prirodne katastrofe,

- druge katastrofe,

- terorizam,

- velike saobraćajne nesreće $\mathrm{i}$

- kontrola vazdušnog prostora.

Svakako da je tim bezbednosti za Igre u Londonu vršio kontrolu kako vazdušnog prostora tako i drugih saobraćajnih prostora, ali je izdvojio četiri glavne pretnje, od kojih je terorizam na prvom mestu po važnosti. Očigledno je da lokacija i sredina diktiraju prioritet, pa se za predstojeće Igre većom pretnjom smatraju građanska neposlušnost i kriminal. Upravo su navedeni primeri pokazatelji da mogu postojati zahtevi opšte bezbednosti, kao i oni specifični za svako podneblje ponaosob.

U Rio de Žaneiru su u toku projekti bezbednosti vezani za predstojeće Igre, a koji se odnose na: poboljšanje nadzornih sposobnosti, poboljšanje trenažnih sistema policijskih snaga, povećanje angažovanosti civilne policije, poboljšanje trenažne sposobnosti civilnih policajaca, poboljšanje operativnog menadžmenta u civilnoj policiji, povećanje angažovanosti vojne policije, 
poboljšanje kriminogene prevencije i dr. Naravno, ovako ozbiljni projekti podrazumevaju koordinisanje sa obaveštajnim službama.

\section{ZAKLJUČAK}

Bezbednost tokom održavanja olimpijskih igara u današnje vreme predstavlja globalni projekat organizacionog odbora olimpijskih igara, MOK, bezbednosnih struktura svih nivoa države čiji je grad domaćin OI, kao i angažovanost velikog broja svetskih bezbednosnih agencija. Rizik nikad nije moguće u potpunosti eliminisati, ali potencijalne pretnje treba prepoznati i razumeti kako bi se mogle ublažiti ili preduprediti. Zahtevi bezbednosti nisu isti za sve olimpijske igre i to zavisi od više faktora, od kojih sama lokacija održavanja igara ima najveću ulogu u njihovom planiranju. Iako terorizam nije na prvom mestu u strategiji nastupajućih OI kao pretnja, ipak se smatra globalnom pretnjom na svim dosadašnjim igrama. Savremena tehnologija u funkciji obaveštajnih i komunikacionih sistema, pored navedenih mera, do sada je potvrdila svoju značajnu ulogu u naporima organizatora da olimpijske igre proteknu što bezbednije i potrebno je nadalje usavršavati.

\section{LITERATURA}

IOC Injury \& Illness Surveillance Study: protecting the athletes' health, retrived May 10, 2017, from http:/www.olympic.org/news/ioc-injury-illness-surveillance-studyprotecting-the-athletes-health/225531

Ksenofont. (1988). Helenska istorija [Hellenic History]. Novi Sad, RS: Matica srpska.

Marković, J., Draganović, M. \& Radošević, I. (2014). Bezbednosni aspekti Olimpijskih igara kroz istoriju [The security aspect of the Olympic Games through history]. In I. Gajić (Ed.), Prva Međunarodna konferencija "Menadžemnt bezbednosti sportskih takmičenja” (pp. 74-82). Belgrade, RS: Fakultet za sport, Univerzitet "Uniuon-Nikola Tesla.

Olympic Deaths. (n.d). Retrieved May 10, 2017, from http://en.wikipedia.org/wiki/Olympic deaths/

Šiljak, V. (2013). Olimpizam [Olympism]. Belgrade, RS: FMS.

Škaro, D. (2012). Organizacija Olimpijskih igara [Management of the Olympic Games]. Zagreb, RH: Mate d.o.o.

Primljeno: 28.05.2017.

Odobreno: 26.06.2017.

Korespodencija:

Prof. dr Violeta Šiljak

Fakultet za menadžment u sportu

Alfa BK Univerzitet

Palmira Toljatija 3

11070 Novi Beograd

Srbija

violeta.siljak@alfa.edu.rs 